\title{
Suppression of Basal Insulin Secretion by Adrenalin in Normal Man and in Patients with Insulinomas
}

\author{
R. C. Turner, G. Hart and D. R. London \\ Nuffield Department of Clinical Medicine, Radcliffe Infirmary, Oxford and Queen Elizabeth Hospital, Edgbaston, Birmingham, England
}

\begin{abstract}
Summary. Basal insulin secretion has been thought to be via a different mechanism from stimulated insulin secretion, partly because it is not similarly suppressed by adrenalin. However, adrenalin normally causes hyperglycaemia, but if it is infused while the plasma glucose is kept constant there is marked suppression of insulin secretion. Sympathetic stimulation modulates basal insulin secretion, and alpha adrenergic blockade impaired the suppression of insulin secretion in response to hypoglycaemia. Four of five benign insulinomas had marked suppression of insulin secretion by adrenalin, but one malignant and one benign insulinoma had little suppression. Both had a raised proportion of their basal plasma insulin as proinsulin, and the impaired suppression of secretion by adrenalin probably signified an undifferentiated tumour.
\end{abstract}

Key words: Basal insulin secretion, adrenalin, alpha blockade, glucose, insulinoma, malignant insulinoma, proinsulin.

Adrenalin suppresses the acute, first phase insulin response to glucose, but has been thought to have considerably less effect on basal insulin secretion [1]. Although an adrenalin infusion in man temporarily lowers the plasma insulin, the concentrations soon rise above the initial level [2]. It has been suggested that the differing responses of the acute and basal insulin secretion to adrenalin signifies there are two separate "pools" of insulin secretion [3]. Further support for this hypothesis has been taken from the differing effect of a glucose infusion on the basal and acute insulin responses [4].

The acute and basal insulin responses may, however, be linked. If the plasma glucose in mild diabetes in man is lowered to a normal value, the basal insulin secretion is reduced and the acute response of insulin to glucose is enhanced [5].

The interpretation of the insulin response to adrenalin infusions is difficult as adrenalin raises the blood glucose and this may affect the observed insulin response. Studies have, therefore, been undertaken in which the insulin response to adrenalin can be observed independent of changes in plasma glucose. In one investigation this was done by keeping the plasma glucose concentration constant with a fish insulin infusion. In a second investigation the response of insulin to induced hypoglycaemia has been studied with and without adrenergic blockade.

Insulin secretion from insulinomas is either autonomous, or is only partly dependent on the glucose concentration [6]. The decreased suppression of insulin secretion to induced hypoglycaemia provides a useful diagnostic suppression test for insulinomas. Adrenalin is an alternative physiological means of suppressing insulin secretion, and its possible diagnostic use has been investigated. An adrenalin infusion in patients with insulinomas causes little hyperglycaemia, and also provides a third means of studying the insulin response to adrenalin independent of changes in plasma glucose.

\section{Materials and Methods}

The effect of an adrenalin infusion on insulin secretion has been studied in 5 normal male students, aged 21-25 who were within $15 \%$ of their ideal body weight [7]. Five patients with benign insulinomas and one patient with a malignant insulinoma were studied. They were aged $23-49$, and were within $15 \%$ of their ideal body weight. They were tested after an overnight fast, except for one of the subjects with a benign 


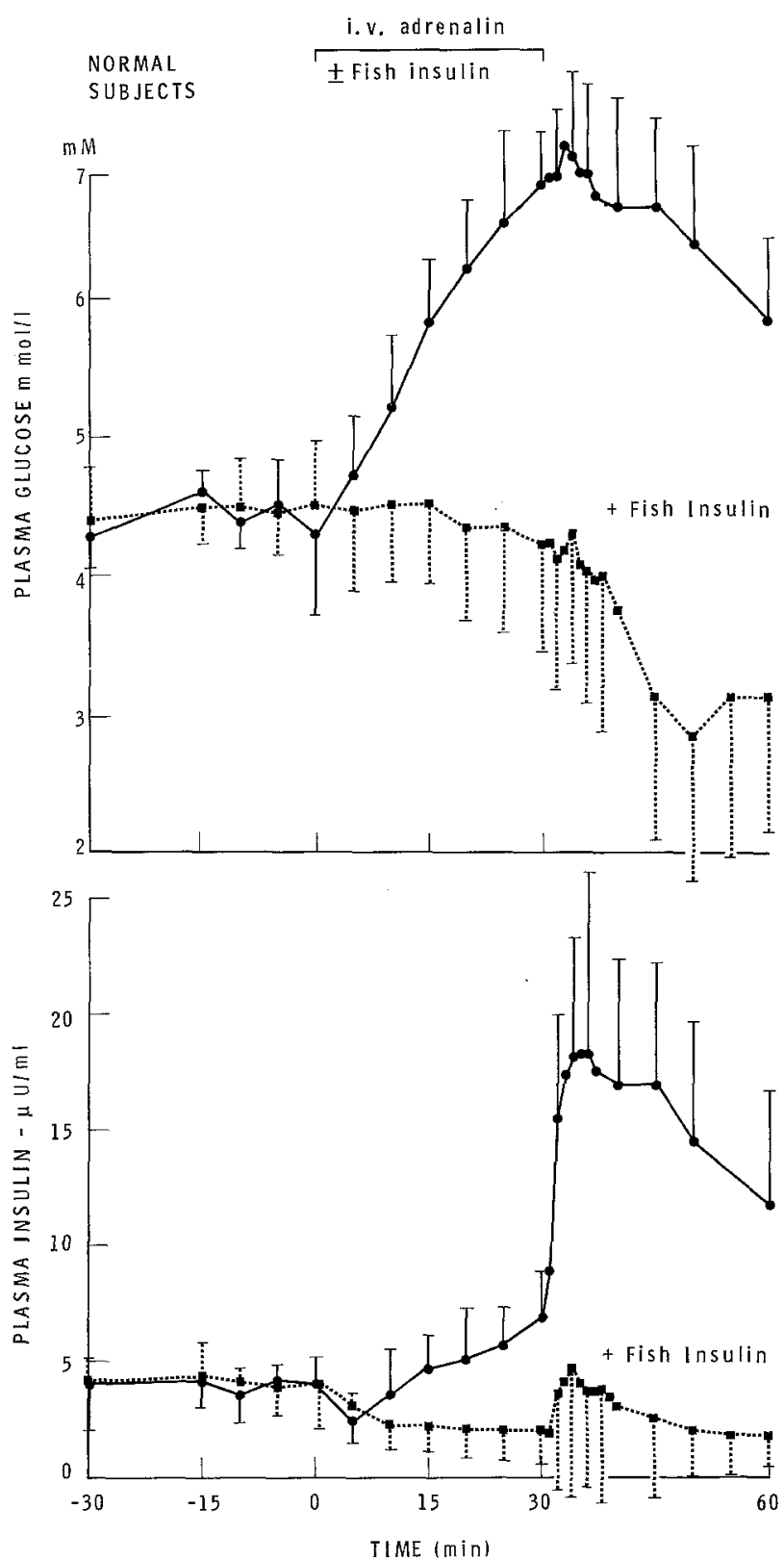

Fig. 1. Plasma glucose and insulin changes in response to a $30 \mathrm{~min}$ intravenous infusion of adrenalin $5 \mu \mathrm{g} / \mathrm{min}$ in 5 normal subjects (mean $\pm 1 \mathrm{SD}$ ). In a separate investigation in the same patients the plasma glucose during the infusion was kept constant by concurrent infusion of circa $4 \mathrm{u} / \mathrm{h}$ fish insulin. The plasma human insulin concentration was then suppressed by the adrenalin infusion, whereas this was otherwise obscured by the insulin response to the glycaemia induced by the adrenalin infusion

insulinoma who had an additional meal at $4.00 \mathrm{a}$. m. to prevent symptomatic hypoglycaemia, and the patient with a malignant insulinoma who had a constant intravenous infusion of $10 \mathrm{~g} / \mathrm{dl}$ dextrose to prevent marked hypoglycaemia.

Blood samples were taken via an IV cannula inserted in the ante cubital fossa. Intravenous adrenalin, $5 \mu \mathrm{g} / \mathrm{min}$, was infused from a syringe pump via a central venous catheter inserted into the other ante cubital fossa. The five normal subjects were studied on a second morning when an additional infusion of fish insulin at circa $4 \mathrm{u} / \mathrm{h}$ was given via a second central venous catheter to keep the plasma glucose constant. This was monitored by means of blood samples taken every $5 \mathrm{~min}$, with the plasma glucose measured using glucose oxidase with an oxygen electrode (Analox), which provided assay results within five min. The rate of insulin infusion was accordingly altered.

The effect of alpha adrenergic blockade on the insulin response to hypoglycaemia induced by fish insulin was studied in six normal students or doctors aged $22-36$, who were within $15 \%$ of their ideal body weight. After an overnight fast and two basal samples, $5 \mathrm{mg}$. IV phentolamine was injected, followed by 0.5 $\mathrm{mg} / \mathrm{min}$ infusion until the end of the test. Blood samples were taken every $10 \mathrm{~min}$. Thirty min after the phentolamine, $0.2 \mathrm{u} / \mathrm{kg}$ i. m. fish insulin was given; this was repeated at 45 and $90 \mathrm{~min}$ [8]. This test was terminated by IV glucose when hypoglycaemic symptoms were noted.

The plasma glucose used in analysis of results was measured using glucose oxidase in a manual method (Boehringer kit). Immunoreactive plasma insulin was assayed in duplicate using charcoal phase separation [9], monocomponent human insulin as a standard (Dr. J. Schlichtkrull) and GP 5 antiserum (Dr. C. Lowy) which has little cross reaction with fish insulin. A disequilibrium assay was used, with a precision $( \pm 1$ $\mathrm{SD}$ of individual estimates) of $\pm 0.4 \mu \mathrm{U} / \mathrm{ml}$. Changes in plasma insulin were assessed using Student's paired $t$ test. The plasma proinsulin in basal samples from the patients with insulinomas was assayed by Dr. L. G. Heding, after separation from plasma C-peptide using solid phase anti insulin antibodies. The plasma C-peptide in the supernatant was assayed by radioimmunoassay [10]. The antibody bound proinsulin was assayed using a C-peptide antiserum, ${ }^{125} \mathrm{I}$ TyrC-peptide and human proinsulin standard (Dr. A. Rubenstein) [11]. The percentage proinsulin in the plasma was expressed in terms of the sum of the proinsulin and C-peptide results.

\section{Results}

In normal subjects the adrenalin infusion caused marked hyperglycaemia $(\mathrm{p}<0.001)$ (Fig. 1). At five min the plasma human insulin was decreased in all subjects $(p<0.05)$, but then rose above the basal value $(\mathrm{p}<0.005$ at $30 \mathrm{~min})$ with a further abrupt increase at the end of the infusion.

When fish insulin was infused in addition to the adrenalin there was a mean fall in plasma glucose of 
INSULINOMA

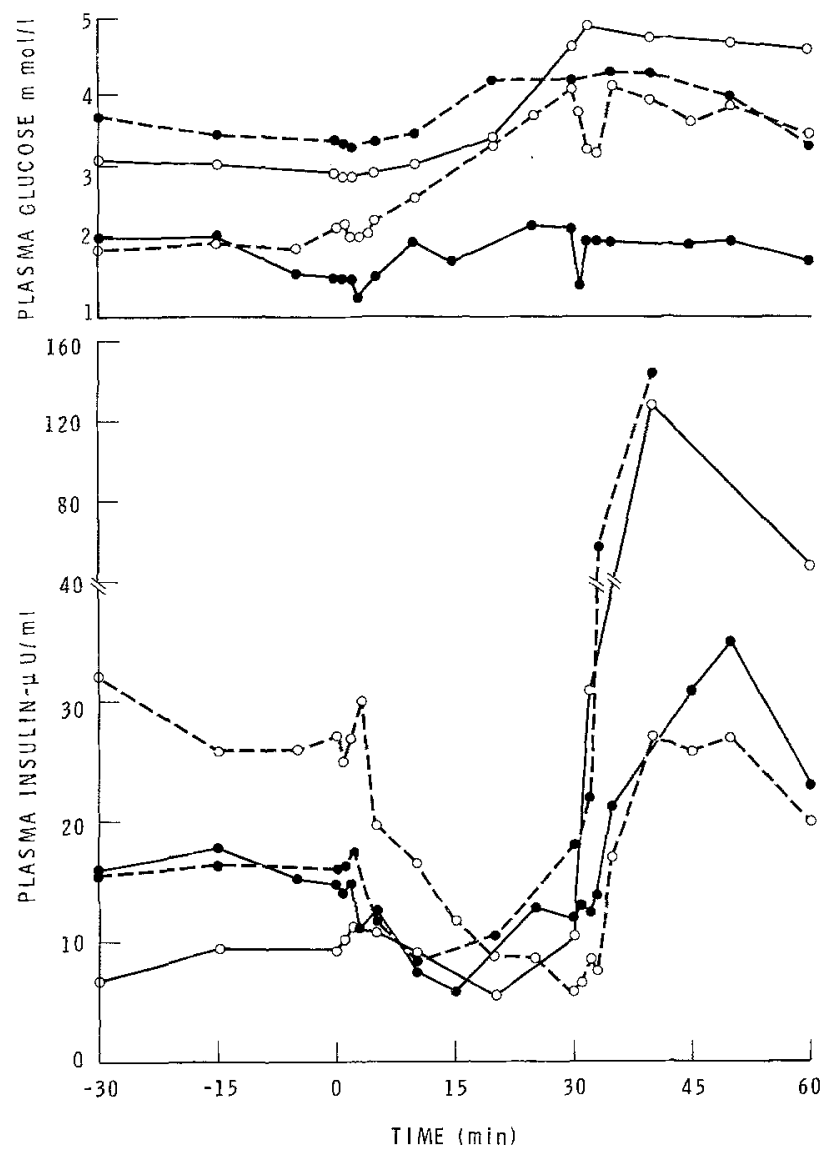

Fig. 2. Changes in plasma glucose and insulin to a $30 \mathrm{~min}$ intravenous infusion of adrenalin $(5 \mu \mathrm{g} / \mathrm{min})$ in 4 patients with insulinomas. Each patient is represented by a different symbol. There was little rise in plasma glucose, and marked suppression of insulin secretion

$0.2 \mathrm{mmol} / \mathrm{l}$ at $30 \mathrm{~min}$. The maximal fall in any subject was $0.4 \mathrm{mmol} / \mathrm{l}$ at $15 \mathrm{~min}$, and $0.7 \mathrm{mmol} / \mathrm{l}$ at $30 \mathrm{~min}$. After the infusions were stopped the plasma glucose fell over the next half hour by a mean of $1.3 \mathrm{mmol} / 1$. During the combined adrenalin and fish insulin infusion there was a sustained decrease in the plasma human insulin from a mean of $4.1 \mu \mathrm{U} / \mathrm{ml}$ to $2.1 \mu \mathrm{U} / \mathrm{ml}$ $(\mathrm{p}<0.01)$. At the end of the infusion the plasma insulin levels returned to the basal value, but then fell to a mean of $1.8 \mu \mathrm{U} / \mathrm{ml}$ pari passu with the delayed hypoglycaemia.

In four patients with benign insulinomas there was only a small rise in plasma glucose following the adrenalin infusion. In these subjects the plasma human insulin concentration was suppressed in response to the infusion (Fig. 2) to a greater degree than in the normal subjects, although in three patients there was a

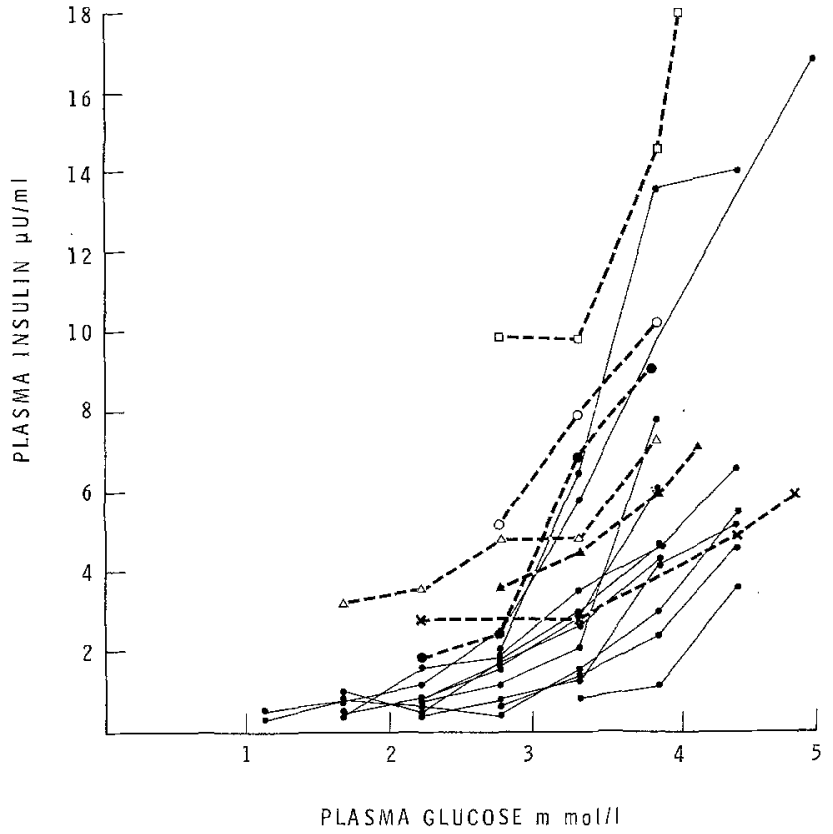

Fig. 3. Plasma insulin in relation to the plasma glucose during hypoglycaemia induced by $0.2 \mathrm{u} / \mathrm{kg} \mathrm{i} . \mathrm{m}$. fish insulin every $45 \mathrm{~min}$. Blood samples taken at 10 min intervals, and plasma insulin represented as means of samples with plasma glucose concentrations within $0.55 \mathrm{mmol} / \mathrm{l}$ groups, with line joining values from each subject. Thin lines represent results from each of 12 normal subjects. Dotted lines represent results from 6 normal subjects following phentolamine, each represented by a different symbol. The subjects who had a phentolamine infusion had reduced suppression of plasma insulin in relation to the fall in plasma glucose compared with the subjects without alpha adrenergic blockade

subsequent rise in plasma insulin towards the basal value at $30 \mathrm{~min}$ when the plasma glucose had increased. There was increased insulin secretion at the cessation of the infusion. In the fifth patient with a benign insulinoma the basal plasma glucose was 4.4 $\mathrm{mmol} / \mathrm{l}$ and rose to $7.5 \mathrm{mmol} / \mathrm{l}$ at the end of the infusion. The plasma insulin $(18 \mu \mathrm{U} / \mathrm{ml})$ did not alter during the infusion, although it rose to $31 \mu \mathrm{U} / \mathrm{ml}$ when the adrenalin infusion was stopped. In the patient with a malignant insulinoma the plasma glucose was 1.4 $\mathrm{mmol} / \mathrm{l}$, and neither it, nor the plasma insulin (310 $\mu \mathrm{U} / \mathrm{ml}$ ) altered during the infusion. These last two patients had a raised proportion of proinsulin in the basal sample (38 and $43 \%$ respectively), whereas the other four insulinomas had between 19 and 28\% proinsulin.

In response to the phentolamine infusion in six 
normal subjects the plasma glucose did not change, and the mean plasma insulin rose from $6.3 \mu \mathrm{U} / \mathrm{ml}$ to $9.4 \mu \mathrm{U} / \mathrm{ml}(\mathrm{p}<0.05)$. In response to the subsequent fish insulin induced hypoglycaemia (Fig. 3), the plasma human insulin concentration was suppressed, but not to the same degree as in 12 normal subjects without $\alpha$ adrenergic blockade ( $\Delta$ insulin/ $\Delta$ glucose, mean $\pm \mathrm{SD}$, normal subjects $60 \pm 15$, with $\alpha$ adrenergic blockade $30 \pm 14 \% / \mathrm{mmol}$ glucose, $\mathrm{p}<0.005$ ).

\section{Discussion}

In normal subjects there is marked suppression of basal insulin secretion by adrenalin if the plasma glucose is kept constant with fish insulin. The insulin infusion is unlikely to have directly decreased insulin secretion, as shown by the lack of effect of both similar doses in man with constant glycaemia [12] and larger doses in dogs [13]. The minimal fall in plasma glucose during the combined adrenalin/fish insulin infusion would itself produce an almost undetectable fall in plasma insulin [6], whereas the adrenalin induced suppression of insulin secretion is comparable to that produced by a considerably greater fall in plasma glucose, as shown at the end of the investigation. Four of the subjects with insulinomas who had little change in plasma glucose also had a reduction of insulin secretion by adrenalin. The previously noted rise in plasma insulin during an adrenalin infusion is, therefore, secondary to the raised plasma glucose rather than a direct response to the adrenalin.

These results show that the basal as well as the acute, first phase insulin secretion is suppressed by an adrenalin infusion. These data do not support the suggestion $[3,4]$ that acute and basal insulin release come from different "pools".

The increased plasma insulin following alpha adrenergic blockade in man is similar to that reported by Robertson and Porte [2], who also showed that beta adrenergic blockade lowered the basal plasma insulin. Basal insulin secretion is therefore partly under sympathetic control. However, alpha adrenergic blockade only partly impaired the suppression of insulin secretion by hypoglycaemia. Thus the basal plasma glucose concentration per se has a considerable role in controlling the basal insulin secretion.

Hypoglycaemia and increased adrenalin secretion are the two physiological stimuli known to decrease the basal secretion of insulin. Although impaired suppression of insulin secretion by hypoglycaemia is a useful diagnostic test for insulinomas [6], the majority of the insulinomas had greater suppression of insulin secretion by adrenalin than normal subjects, probably because of their less marked glycaemic response. Adrenalin cannot, therefore, be used as a diagnostic test.

It has been suggested that one might be able to discriminate between benign and malignant insulinomas by the decreased response of the latter to diazoxide [14]. Although the malignant insulinoma we studied had impaired insulin suppression by adrenalin (as did the malignant insulinoma with the same dose of adrenalin reported by Graber et al. [15]), a similar response was seen in the benign insulinoma which also secreted a high proportion of proinsulin. Both tumours were therefore probably undifferentiated [16], and although an adrenalin infusion might give an indication of the degree of differentiation it is unlikely to give direct evidence of malignancy. The proportion of proinsulin found in the basal plasma insulin $[11,17,18]$ might give similar information.

Acknowledgements. We are grateful for the support of Professor D. J. Weatherall and Professor R. Hoffenberg, to Dr. T. M. Chalmers, Dr. M. G. Fitzgerald, and Dr. T. D. R. Hockaday for allowing us to study their patients, and for the assistance of Miss P. Harding and Mrs. E. Harris. This work was supported by grants from the British Diabetic Association, the Oxford Regional Health Authority (Teaching), and the Oxford Hospital Services Development Trust.

\section{References}

1. Lerner, R. L., Porte, D.: Epinephrine: selective inhibition of the acute insulin response to glucose. J. clin. Invest. 50, 2453-2457 (1971)

2. Robertson, R. P., Porte, D.: Adrenergic modulation of basal insulin secretion in man. Diabetes 22, 1-8 (1973)

3. Porte, D., Bagdade, J. D., Lerner, R.: Basal insulin secretion: the abnormality of obesity and its relation to a two-comparmental model for insulin release. Excerpta medica, Int. Cong. Series (Amst.), 544-550 (1971)

4. Porte, D., Pupo, A. A.: Insulin responses to glucose: evidence for a two pool system in man. J. clin. Invest. 48, 2309-2319 (1969)

5. Turner, R. C., McCarthy, S. T., Holman, R. R., Harris, E.: Beta cell function improved by supplementing basal insulin secretion in mild diabetes. Brit. med. J. 1976 I, 1252-1254

6. Turner, R. C., Harris, E.: Diagnosis of insulinomas by suppression tests. Lancet 1974 I, 188-190

7. Net weight standard for men and women. Statistical Bulletin (Metropolitan Life Assurance Co.) 40, 1-4 (1959)

8. Turner, R. C., Johnson, P. C.: Suppression of insulin release by fish-insulin-induced hypoglycaemia with reference to the diagnosis of insulinomas. Lancet 1973 I, 1483-1485

9. Albano, J. D. M., Ekins, R. P., Maritz, G., Turner, R. C.: A sensitive, precise, radioimmunoassay of serum insulin relying on charcoal separation of bound and free hormone moieties. Acta endocr. (Kbh.) 70, 487-509 (1972)

10. Heding, G.: Radioimmunological determination of human Cpeptide in serum. Diabetologia 11, 541-548 (1975) 
11. Turner, R. C., Heding, L. G.: Plasma proinsulin, C-peptide and insulin in diagnostic suppression tests for insulinomas. (in press)

12. Morishta, S., Shima, K., Tanaka, R., Tarui, S.: Effects of exogenous insulin on secretory function in B-cells in man. Abstracts VI Int. Congr. Endocr., p. 96. Hamburg 1976

13. Sando, H., Kanazawa, Y., Kuzuya, T.: Effect of bonito insulin on endogenous insulin secretion in dogs. Amer. J. Physiol. 218, 1357-1362 (1970)

14. Berger, M., Berchtold, W., Wiegelmann, H., Drost, H., Zimmermann, H.: Suppressibility of serum insulin in patients with insulinoma by somatostatin, diazoxide and diphenylhydantoin. Diabetologia 11, 329 (1975)

15. Graber, A. L., Porte, D., Williams, R. H.: Clinical use of diazoxide and mechanism for its hyperglycaemic effects. Diabetes 15, 143-148 (1966)

16. Creutzfeldt, W., Arnold, R., Creutzfeldt, C., Deuticke, U., Frerichs, H., Track, N. S.: Biochemical and morphological investigations of 30 human insulinomas. Diabetologia 9, 217-231 (1973)
17. Gutman, R. A., Lazarus, N. R., Penhos, J. C., Fajans, S. S., Recant, L.: Circulating proinsulin-like material in patients with functioning insulinomas. New Eng. J. Med. 284, 1003-1008 (1970)

18. Sherman, B. M., Pek, S., Fajans, S. S., Floyd, J. C., Conn, J. W.: Plasma proinsulin in patients with functioning pancreatic islet cell tumours. J. clin. Endocr. 35, 271-280 (1972)

Received: April 20, 1976, and in revised form: October 6, 1976

Dr. R. C. Turner

Medical Tutor

The United Oxford Hospital

Nuffield Dept. of Clinical Medicine

The Radcliffe Infirmary

Oxford OX $26 \mathrm{HE}$

England 